\title{
An Ethnographic Investigation of Code Switching and Mixing in Pakistan: A Case Study of Nine-Year Old Child, Alia
}

\author{
Jahangir Bhatti ${ }^{1} \&$ Shabana Sartaj ${ }^{2}$ \\ ${ }^{1}$ Ontario Institute of Educational Studies, University of Toronto, Canada \\ ${ }^{2}$ Department of English, Sindh Agriculture University, Tandojam, Sindh, Pakistan \\ Correspondence: Shabana Sartaj, Department of English, Sindh Agriculture University Tandojam, Sindh \\ Pakistan. E-mail: ssartaj@sau.edu.pk
}

Received: January 8, 2019 Accepted: February 2, 2019 Online Published: February 24, 2019

doi:10.5539/ijel.v9n2p210 URL: https://doi.org/10.5539/ijel.v9n2p210

\begin{abstract}
Bilingualism has special designation in learning of language especially in countries where English is second or third language. Bilingualism sketches the concept of a speaker that either mixes or switches two or different codes while making an utterance. In that perspective, the present study is designed as an ethnographic research to validate the notion of bilingual action of speech turning in Pakistan. This case study of nine year old child named Alia has been conducted to formulate the situation of bilingualism in multilingual society of Pakistan. In that regard the researcher recorded the dialogues of a child while taking part in different roles. The speech of the child was later analyzed to investigate the influence of bilingualism on it. The two languages were focused Urdu and English with the little extent of Punjabi code. Various reasons were researched for finding out the basic factors that led to switch or mix codes within an utterance. The parents of a child Alia were also interviewed that led to find specific factors of their child to code switch and mixes. The factors include bilingual environment, partners, mother tongue, social interactions and medium of education in school.
\end{abstract}

Keywords: codes switching, code mixing, bilingualism in Pakistan, case study

\section{Introduction}

"Alia: main aaj subah morning main uthi thi aur main garden main gai thi”

This type of sentences can often be heard in Urdu with code mixing in a single utterance. In countries like Pakistan, the usually English language words are taken for code switching or borrowing because English is the official language of Pakistan and according to Rehman (2011) a status symbol. The usage of this mixed language shows the bilingualism of the country or community. According to David Crystal (1997), around in two-thirds of whole globe, the offspring are usually nurtured in bilingual environment. Whereas, Trask (1999) pointed out that more than $70 \%$ of earth's population is thought to be bilingual. Furthermore, code-switching is regarded as the sociolinguistic phenomenon which is mostly prevalent in multilingual and bilingual communities. According to Wardaugh's (1986) findings, a language that speaker opts at point to speak is the code, whereas, the system refers to point of sharing codes in form of communication between two people in situation. This adds further about bilingual speakers take a stance of one code in speaking and takes an opportunity to switch or mixes the code with other. It has been observed that a very slight or negligible difference is found between code-switching and code mixing. The occurrence is countered in sentences (inter-sentential) or in a single utterance (intra-sentential). Pakistan is one among such countries where majority of people are bilingual or multilingual. Sindhi, Pushto, Balochi and Punjabi are the main local languages of Pakistani people, Urdu is the national language of Pakistan whereas English is the official language in academia and workplaces. Pakistani children are countered with two languages at same time do code-switching in their speech. This paper focuses on investigating various questions as to why the young learners mostly switch English Code while speaking; why it is significant to switch English Code; what are the contexts and reasons due to which the learners are required to switch the English Code. Thus, the present paper focuses on investigating and knowing the practicality of switching English Code firstly; secondly the needs of today's world to switch English Code; and finally, the contexts and reasons which lead the young Pakistani learners to switch the English Code in their speech. 


\section{Literature Review}

\subsection{Bilingualism}

Grosjean (2004) admires majority of researchers for the tendency to have agreement on bilinguals that speak two or more codes. These bilinguals have specific features. They learn different codes to achieve variety of purposes. This leads to rare fluency in all lingual skills to manage in speaking both codes. It is the fluency that merely relies on want and its usage. Level of proficiency can be changed according to the environment and needs of the language. Meisel (2004) agrees with Grosjean (2004) that the bilingual people or communities have two different languages that are used to communicate to accomplish goals in different occupations, situations and in workplaces.

\subsection{Code-Switching}

Grosjean (2004) defines the term code switching as a shift to the new language, a word, a phrase or a complete sentence. While in Stockwell's (2003) point of view code-mixing is the switch between two different languages that can occur within one utterance. Muysken (2000) gave his opinion that intra-sentential code-mixing indicates a less proficiency skill. Moreover, ideal bilingual people usually switch according to changes in particular event (interlocutor, topics). Grosjean (1995) informs about bilingual speech during code-mixing or two languages which are active at one time. If both the languages are active at the same time, then we can say that person is in bilingual mode. Code-switching is quite often subconscious. The people who do code-switching are sometimes not aware that they do code-switching. In most of the cases, a person switches the code in languages according to the need of situation and interlocutor. If a person is code-mixing while talking, it means that other person also knows the same languages which he/she is using (Beardsmore, 1989). Houwer (1990) pointed out that mostly young children mix words from other languages. We can also see code-switching or mixing as that it can be used as the strategy to learn a new language. Children can also learn many new words by this phenomenon. He also revealed that children rarely use code-mixes in front of a monolingual speaker. The study of code-switching can be done by keeping in view the two major issues, as (1) the functional issues that why the code-switching occurs; and (2) the formal or syntactic issues, that where it occurs. The code-switching and mixing require similar aspect in both the cases that are borrowing from other language to such a degree that borrowed element be integrated or induced to different code (Edwards, 1994). Intra-sentential switches occur in the middle of the sentences (Muysken, 2000). There can also be a switch of codes within a simple utterance without any associated topic change. It can be expressed that code-mixing and intra-sentential code-switching is the same thing. Intra-sentential code-switching have use of the elements that is two codes in one utterance.

\subsection{Borrowing}

Many researchers believe that borrowing and code-mixing are same, but like bilingualism and code-mixing there are contradictions for borrowing as well. Language mixing can also be called borrowing. Children who are living in bilingual culture learn languages from both the cultures and they quite often mix single word. Therefore, it is challenging to differentiate between mixing and borrowing (Lyon, 1996). Some researchers have also called borrowed words as loan words. The items which are borrowed do not have a fixed status in the beginning, and until many people do not start using a word frequently, people can adapt it, and the same person does not even use same phonological form in the same utterance. It is hence difficult to say for a word in a bilingual conversation that it is an example of code-switching or not. The borrowing has either a word borrowed from other language if is integrated either phonologically or morphologically to the primary language. The code-switching involves a switched element which is not integrated. However, a total shift to the other language is observed (Grosjean, 2004) but Muysken (2000) argues that if we see this definition there may be different degrees as phonological adaptations for borrowed items, secondly, it cannot be said with surety that all adapted items can be categorized as code-mixing. For any given word in a bilingual discourse that appears to be a loan word or a borrowed word is often difficult to decide whether it represents code-switching (Romaine, 1989). If the item is adapted phonologically or morphologically to one of the languages which are being spoken, it is borrowing, but if it is not the case, this is code-switch. One possibility is that a person code-switches one word in another language and afterward it is adapted morphologically or phonologically in the base language because it is used again and again. It is true that some bilinguals prefer to code-switch than borrowing and some words are better switched than borrowed (Grosjean, 2004).

\subsection{Reasons of Code Switching Among Bilingual Children}

There may be situations or domains in which bilingual children usually use only one of their two languages, e.g., a child may use only English at school but speak only Greek with his or her mother at home. As a result, he or she may have more significant English school vocabulary, and he can have a better vocabulary in Greek for 
those activities which he only does at home because each topic is strongly associated with a language (Saunders, 1988). Specific words may be associated with specific situations in which only one language is regularly used, and the equivalent vocabulary for those words in the other language may not be known yet (Grosjean, 2004). A pervasive problem for bilingual children is that the language which is only spoken at home will be spoken with less grammatical accuracy as compared to the dominant official language of the community, and the active vocabulary for the language which is only spoken at home will be much less than the language which is widely used. The child uses mixing because he seems to lack the equivalent in the appropriate languages. Furthermore, bilingual children, who do not know enough words in one of the two languages, prefer to insert lexical items from the other language in their sentences rather than producing incomplete sentences or nuclear structures. Beardsmore (1989) further added that an activity which is carried in one language, sometimes proved to be challenging to do in another language with the same fluency. If a bilingual child has the choice to use either of his two languages, then the one which he will choose will be the most probably his dominant language. Secondly, "dominant" is used concerning the language in which more code mixing is used. The language which is more mixed will be the dominant language of the child. However, this dominance will not be shown when the bilingual child will be talking to a person who knows only one language. Lanza (2004) supports the view that the switching bilingual children do, depends on their language of dominance. It is challenging to find a person, child or adult, who does not have any influence on his language in some way or other in today's global village world. The children of the immigrants move to another country, so their language and their input become different from their original homeland. Moreover, children adopt new words for some new concepts which they find in a new culture. Lyon (1996) illustrated that children can start mixing languages if they hear the language which contains mixed words or borrowed words. Many researchers like Arnberg (1992) emphasized on the role of parental and social input as sometimes parents are unaware of the fact that they are mixing languages. Lanza (2004) says that some of the factors for code-mixing can be dominance, linguistic input and interactional aspects of bilingualism. It should also be seen that whether in the language of the child code-mixing is there due to linguistic input or it is the norm of the society as in every bilingual community social behavior is different. The behavior of the parents, i.e., how they respond when their child mixes the languages have critical role in the linguistic development of a child. Although, even the parents are aware of the fact that language mixing should be avoided but still they themselves do not avoid. So, there is a difference between what should be done and what is actually happening in society and community (Lanza, 2004). At first, code-mixing occurs when a child does not know a language, but later it becomes his or her communicative strategy.

\section{Methodology}

\subsection{Participants}

In pursuit of the proposed study, the researcher found a family who had a nine years old daughter. During the conversation, it was observed that she was a bilingual child, and she used to switch code a lot during her conversation. So, it was a perfect ethnographic case to carry research further in finding out the reasons that why she does so? The researcher, during the course of time found many aspects and reasons of the code mixing and switching of children Pakistan.

\subsection{Research Method}

The methodology is one of the most critical points of research. In order to achieve the answer of questions effectively, an ethnographic case study approach was adopted that focused to get natural data in a natural setting and the results was helpful in getting more information about the participants' language behavior. The meeting with family was scheduled for one month so that the participants do not feel any hesitation. The subtleties of the participants' meaning cannot be understood unless researcher immerses himself/herself in the culture (Dornyei, 2007). According to Dornyei (2007), case study researchers in most of the cases combine a variety of data collection methods such as interviews, observations and field notes etc. Johnson (1998) emphasized that the basic aim of the ethnography is "to describe and interpret the culture behavior, including communicating behavior of a group". In this study, a young bilingual child will be observed to reveal some aspects of language behavior. As ethnographic study gives an insight on cultural behavior and case study will focus on the detailed description of a specific bilingual child (Mackey \& Gas, 2005). The conversation between participant and researcher was conducted. The primary data is taken by recording the conversation between participant and researcher. The social behavior and language mixing of the child gave me an opportunity to find the reasons of code-switching between two languages. The situation in that was context about participant is talking.

\subsection{Field of Research}

The young bilingual child on whom the research was conducted was Clifton Karachi, Pakistan. 


\subsection{Research Subject}

The Research subject is a nine-year-old girl who can speak and understand two languages, Urdu and English. She can read and write in English and she has developed some receptive oral skills in another language, Punjabi, i.e. she can understand Punjabi to some extent, but she cannot speak it. Father of the child can speak, read and write in English, Urdu and Punjabi but mother of the child can speak, read and write in Urdu and Punjabi but she cannot speak, read and write in English except few sentences. She can understand English with a little difficulty. The parents only speak Urdu with the child at home and they don't speak Punjabi and English with children. Parents communicate in Urdu with each other, but they use Punjabi as a private speech, i.e. when they want to speak something which they don't want their children to understand as children cannot understand Punjabi fully. They also use Punjabi sometimes when they talk to their relatives. The child is studying in a school where she speaks only one language and that is English. She cannot use Urdu there because it is not allowed in the school.

\section{Data Analysis}

The recorded material was carefully transcribed and then thoroughly studied and analyzed. Some examples given in paper show mixing patterns in Alia's speech and researchers have discussed the observed reasons of code switching or mixing. In the given examples all the English words are italicized because at some places there are so many mixed words in a single utterance. However, if the researchers have given an example for defining the reason, they have bolded those words which are used to explain the reason.

$$
\begin{aligned}
& \text { English }=\text { Italics } \\
& \text { Explained } \text { words }=\text { bold }
\end{aligned}
$$

EXAMPLE1:

1. Alia: wo wali game kyun nahe khaelti .

= Why don't you play that game?

2. socho ap teacher ho ma child hun line bnao uske ander.

=Imagine that you are a teacher, I am a child. Make a line inside it.

3. ap ne maire liye line draw karnee ha ma apke lie koi eline draw karun gee.

=You will draw a line for me and I will draw a line for you.

4. Aur ap ne uske sath kuch banana ha.

$=$ And you will make something with that.

5. Aur time par karna ha. $=$ And do it in time.

6. Time run ho raha ha.

=Time is running.

7. jo kar lay ga wo jeet jaye ga.

One who will do will win.

8. Bachay jo saray around han na wo btaen gay k kon jeeta ha.

$=$ Children who are around will tell that who has won.

In this example, Alia was explaining to the researcher that how to play the game, which she wanted researcher to play with her. In a single utterance, Alia has switched the code. She has used many words of English and all of them are not included in borrowing. In turn (1) she has used the word game which is almost a borrowed word. It cannot be said entirely because if it is used as a verb, then this word is not used instead Urdu equivalent of it is used. In turn (2) she has used the word child; she could have used the Urdu equivalent of this word. However, she has used the word "child." Because in her school she uses this word more. Then in the same turn, another word used is "line" which is a borrowed word. In turn (3) Alia has used a word "draw." This word is also another example of code-switching in Alia's speech. Although she knows the Urdu equivalent of "draw" as she used that further in her speech. However, since she uses this word in school more frequently, she used this word here. She is explaining about a game which she also plays at school. At school, she does not mix code in her language because all the speakers are monolinguals who can understand and speak only one language and that is English. However, when she comes home, most of the times she is talking to bilinguals who can at least understand English, if do not speak. Therefore, if she is explaining anything related to her school, she uses those words which she also uses in school and same is the case with those activities which she does at school and 
repeats them at home. All the instructions in the school given by teacher are also in English. So, in turn (5), turn (6) and (8) she used the words "time," "time run" and then "around," these words also have their Urdu equivalents. Her teacher also gives her instructions this way, so she also used these words. The word around is a typical example of mixing although time is used as a borrowed word, as Urdu equivalent is rarely used. It is phonologically adapted. We can call it a borrowed word in Urdu. In this example, Alia has used those words which she also uses in school, as she is explaining about a game which is also played at school.

EXAMPLE 2:

1. Researcher: acha Alia ap class ma kis tarah bethti ho?

$=$ What is your sitting arrangement at school?

2. Alia: one table par six people.

$=$ At one table six people.

3. Aur one colour dia hua ha.

$=$ And one colour is given.

4. jisko kuch bhee nahe ata jisko help chhaye wo purple ha.

$=$ One who knows nothing and who needs help he is purple.

5. Jo second level ha wo green ha.

$=$ the second level is green.

6 Jo highest level pe ha wo yellow ha.

$=$ One who is at the highest level he is yellow.

7. Aik blue bhee ha aik purple ha.

One is blue also and one is purple.

8. Researcher: ap kis level par ho?

$=$ At what level you are?

9. Alia: ma green. Yellow ma sirf four people hotay han.

$=\mathrm{I}$ am green. There are only four people in yellow.

10. Researcher: yellow par char to baki par?

$=$ If four at yellow then what about others?

11. Alia: baki par six. Aur blue par four.

$=$ Six at rest. And four at blue.

12. Ma lowest se highest kartee hun. Red, purple, blue, green, yellow

$=$ Ok I will do from lowest to highest. Red, purple, blue, green, yellow.

13. Researcher: ap green par ho?

$=$ Are you at green?

14. Alia: han

$=$ Yes.

In example 2 when researcher asked the child that what is her sitting arrangement in class. She told that children are allotted different tables of different colors according to their grades and performance in class. While describing the setting, the child has used all the names of colors in English instead of Urdu. In turns (4), (5) and (6) the child has used green, yellow and purple. Then in turn (7) and (11), she has used purple and blue. Moreover, later in turn (12), she has used all the names of colors. There are some reasons for it. Most of the names of colors are used in Urdu as they are used in English. Here the typical definition according to which, if a word is borrowed, it should be morphologically or phonologically adapted cannot be used because the color names are used in the Urdu language with the same pronunciation as they are used in English. The second reason is that even the child's parents use the names of colors in English instead of calling the names of colors in Urdu, so the child also uses the names in Urdu.

Moreover, third reason is that the child always hears and uses the names of colors in English in her school, so all 
the input which she is getting regarding names of colors is in English. It is in turn (2) and (9) the child has used words" four people" and "six people respectively." This is again mixing because the child uses these words in school, so she is using here. The child first mixes the language, but then child takes it as a communicative strategy.

EXAMPLE THREE

(a)

1. Researcher: Mubina apse choti ha?

$=$ Is Mubina younger than you?

2. Alia: jee. $=$ Yes.

3. Researcher: kitni?

= How much?

4. Alia: six ha.

$=$ She is six.

5. Researcher: acha?

$=$ Is it?

6. Alia: jaise bhee aye ha maire se jhut bolay ja rahe ha $\mathrm{k}$ ma five hun five hun five hun.

$=$ Since she has come she is telling me a lie that I am five, I am five, I am five.

7. Ma n saba phupho se poocha ha.

$=\mathrm{I}$ have asked Saba Auntie in the morning.

8. Saba phupho n kaha ha six ha.

$=$ Saba aunty has said that she is six.

9. Researcher: aur ap?

$=$ And $\mathrm{u}$ ?

\section{Alia: nine.}

$=$ Nine.

11. Mubina: ap ten ho.

$=$ You are ten

12. Alia: nahe hun.

$=\mathrm{I}$ am not.

(b)

13. Alia: ma aj six o' clock uthi the.

= I woke up at six o' clock.

14. Researcher:Ap kitne baje sotee ho?

$=$ At what time do you sleep?

15. Alia: ma nine o' clock sotee hun

$=$ I sleep at nine 0 ' clock.

16. Mubina: ma seven o' clock sotee hun

= I sleep at seven o'clock.

17. Alia: ma kabhi kabhi eight o' clock b sotee hun. Aik dafa auntie $n$ mujhey itni early uthaya tha. five o' clock utha dia tha.

$=$ Sometimes I sleep at eight $0^{\prime}$ clock. Once aunty woke me up so early. She woke me up at five. 
(c)

18 .Alia:acha ye game ha is ma likhte nahe han.

$=\mathrm{Ok}$ this is a game. You don't write in it.

19. Ye wo wali game ha twenty four days.

$=$ It is that game twenty four days.

20. Nahe twenty three days.

$=$ No twenty three days.

21. Aik person ha na aise kar sakta ha one two three.

$=\mathrm{A}$ person can do one two three.

22. Jaise ap one nahe kah saktee ho.

$=$ Like you can't say one.

23. Two, ten aur three kah saktee ho agar apka dil kar raha ha two kahne ko ap kah do gee four, five. Ya six, seven.

= You can say two, ten or three . if you want to say two you will say four, five or six, seven.

24. Likhte nahe han bas aise he kah dete han.

$=$ You don't need to write just say like this.

25. Researcher: to is se kya ho ga?

$=$ What will happen by this?

26. Alia: jo last one ho ga na jo kahay ga twenty, twenty three, usko dare milay gee.

$=$ One who will be at last who will say twenty, twenty three he will get dare.

27. Jo bhe end par kahay ga na ga na twenty three pe us ne aik dare btanee ha. Us ne aik dare karni ha.

$=$ One who will say at end at twenty three he will tell a dare. He will do a dare.

In Example three (a) when I asked Alia about Mubina's (Alia's cousin) age, she told me that she is six. Instead of telling the age using digits in Urdu she told in English. For example "six" is called "chay" in Urdu. But she used six instead of "chay". In turn (4) and (8) she has used six and in turns (6) and (10) she has used other two numbers five and nine respectively.

Similarly, in example three (b) when Alia was asked that when does she wake up, again she told explained that she wakes up at six o' clock in turn (13) and she told that she sleeps at nine o' clock in turn (15). In another example she did not say numbers using the Urdu language. In turn (17), she used eight and five. In the example three (c), Alia was telling about a game which she wanted to play. So she was explaining that how to play the game. In this example she used all the numbers using the English language. These are not borrowings, and these are examples of code-mixing because we say numbers in Urdu. The digits can be said in Urdu, but in all these examples Alia said these numbers in English and she did not say a single number in Urdu despite the fact that she was speaking Urdu. When it was observed and recorded, the specific reason for that was found that she did not know how to count in Urdu and this piece of her talk further clarified the researchers' point. When she asked that at what time the researcher will come to their home? The researcher told that "gayara" baje tak. In reply she requested to tell her time in English or translate gayara in English. It was told that it is eleven o' clock. She further told that she only knows Urdu counting till five digits. After that, she doesn't know how to say digits and what are the Urdu translation of these English digits.

\section{Discussion and Conclusion}

This research was conducted to find out the reasons of code switching and code mixing among bilingual children. The targeted family for the research in Pakistan had Urdu as their mother tongue, but still they were not entirely successful in making their child proficient enough in her mother tongue. Moreover, there were several reasons for it. Although it is difficult, but not impossible to maintain a single language in current global world and mixed society. If parents are aware of the fact, then they can take several steps to give their children an equal input in both the languages. Moreover, other than primary research question, another aspect of influence of Punjabi (the local language) was also observed which is not discussed in detail but just as one of the sub finding of the study. In a conversation between two bilinguals, it is natural that they mostly mix different codes, therefore it can be 
conceived that code-mixing or switching is a part of bilingualism. The research was a case of a successive bilingual, i.e., she first learned one language and then another language at school. She is an unbalanced bilingual, or it can be assumed that she is dominant bilingual because in one language her proficiency is high. She can also be called a receptive or passive bilingual. There are many reasons due to which she does code-switching, but few are worth sharing here. One of the reasons is being in the environment where child has no more exposure to Urdu or a friend who can speak to her in Urdu. At home, the child does not get much time to talk to her parents as her father and mother are busy most of the times. So, it means that she is unable to get much linguistic input. According to her mother, she talked less to native speakers of the specific language all the time. Her mother also told that when she went to school, she did not speak at all for first three months. She went to school but only for two weeks. During interview, Alia's mother told that her Urdu is perfectly fine. So, it was concluded that her parents not only mix the words themselves at the first, but they are not even aware of it. Moreover, as a result Alia also does code-switching and parents do not give any feedback on her speech, or they do not correct her neither they tell her any vocabulary for the words. Therefore, Alia never corrected herself. A child first mixes the language, but later it becomes his or her communicative strategy. Another critical factor is that Alia cannot read and write in Urdu as reading in any language is an important source to get the vocabulary of different words in any language. As Alia doesn't communicate much with her parents so books can be an important source to provide her with vocabulary. When she will have adequate vocabulary for different words, she shall not code-switch between the different languages. Whenever Alia talked about some activities which she does at school, she mixes the language and since her most of the time is spent at school and she is more proficient in English as compared to Urdu. This proficiency in English means she used many English words. She does not mix words in her English language because she talked to monolingual speakers at her school so if she had mixed words, nobody would have understood at her home, her parents and other people with whom she talks were all bilingual so at that time she mixed the codes. Moreover, another point is that she was just nine years old and her linguistic development seemed to be process so it is possible that with the passage of time her vocabulary may increase and then she may not mix the code.

\section{Suggestions}

It is difficult to maintain a language in a community or surrounding where all the speakers are from other languages. Children can be provided with books, movies and other sort of linguistic input in the marginalized language of a society and if exposure to any language is not enough then the parents can give exposure in many ways. For example, if parents are living in a society where they think that in order to maintain their native or national language, they should give some extra input to their children, they can take help from media in this respect. Additionally, if parents seriously want to maintain a language, they can shift to a place where more native speakers of that language are living so that a child can get linguistic input and exposure in that language. Community gatherings and meetings can also be arranged where children can talk to the native speakers that may increase their language proficiency. One should also consider another aspect while seeing the code-mixing behavior in a bilingual child and that is individual differences. For different people, reasons for code-mixing can be different.

\section{References}

Arnberg, L. N. (1992). Language awareness and language separation in the young bilingual child. In R. J. Harris (Ed.), cognitive processing in bilinguals. Amsterdam: North Holland. https://doi.org/10.1016/S0166-4115(08)61512-5

Beardsmore, H. B. (1986). Bilingualism: basic principles. Clevedon: Multilingual Matters Ltd. https://doi.org/10.3138/cmlr.45.1.192

Crystal, D. (1997). English as a global language. Cambridge: Cambridge Universtiy Press. Retrieved from http://www.cambridge.org/9780521823470

De Houwer, A. (1995). Bilingual language acquisition. In P. Fletcher \& B. MacWhinney (Eds.), The handbook of child language (pp. 219-250). Oxford: Blackwell.

Dornyei, Z. (2007). Research Methods in Applied Linguistics. UK: Oxford University Press.

Edwards, J. (2004). Foundations of bilingualism. In T. K. Bhatia \& W. C. Ritchie (Eds.), The handbook of bilingualism. Oxford: Blackwell publishing. https://doi.org/10.1002/9780470756997.ch1

Grosjean, F. (1982). Life with two languages: an introduction to bilingualism. Cambridge, MA: Harvard University Press.

Grosjean, F. (2004). Studying Bilinguals: Methodological and conceptual issues. In T. K. Bhatia \& W. C. 
Ritchie (Eds.), The handbook of bilingualism. Oxford: Blackwell publishing. Ch2.

Grosjean, F. (1995). A psycholinguistic approach to code-switching. In Milroy and Muysken, pp. 259-275.

Johnson, J. C. (1998). Selecting ethnographic informants. Newbury Park, Calif.: Sage. https://dx.doi.org/10.4135/9781412973588.n30

Lanza, E. (2004). Language mixing in infant bilingualism: a sociolinguistic perspective. New York: Oxford University Press.

Lyon, J. (1996). Becoming bilingual: language acquisition in a bilingual community. Clevedon: Multilingual Matters.

Mackey, L., \& Gass, M. S. (2005). Second Language Research: methodology and design. New Jersey: Lawrence Erlbaum Associates Publishers.

Meisel, M. J. (2004). The bilingual child. In T. K. Bhatia \& W. C. Ritchie (Eds.), The handbook of bilingualism. Oxford: Blackwell publishing. Ch4.

Muysken, P. (2000). Bilingual speech: a typology of code-mixing. Cambridge: Cambridge University Press.

Muysken, P. (2004). Two linguistic systems in contact: grammar phonology and lexicon. In T. K. Bhatia \& W. C. Ritchie (Eds.), The handbook of bilingualism. Oxford: Blackwell publishing. Ch6.

Romaine, S. (1989). Bilingualism. Oxford: Blackwell Publishers.

Saunders, G. (1988). Bilingual children: from birth to teens. Clevedon: Multilingual Matters Ltd.

Stockwell, P. (2003). Sociolinguistics: resource book for students. New York: Routledge.

Trask, L. R. (1999). Key concepts in language and linguistics. New York: Routledge.

Wardaugh, R. (1986). An introduction to sociolinguistics. Oxford: Blackwell Publishing.

\section{Copyrights}

Copyright for this article is retained by the author, with first publication rights granted to the journal.

This is an open-access article distributed under the terms and conditions of the Creative Commons Attribution license (http://creativecommons.org/licenses/by/4.0/). 